\title{
Treponema peruense sp. nov., a commensal spirochaete isolated from human faeces
}

\author{
Claire Belkhou, ${ }^{1,2 *}$, Raul Tito Tadeo 1,2, Rodrigo Bacigalupe ${ }^{1,2}$, Mireia Valles-Colomer ${ }^{3}$, Samuel Chaffron, Marie Joossens ${ }^{5}$, \\ Alexandra Obregon ${ }^{6}$, Luis Marín Reyes ${ }^{7}$, Omar Trujillo ${ }^{8}$, Geert R. B. Huys ${ }^{1,2}$ and Jeroen Raes R.,2* $^{1, *}$
}

\begin{abstract}
A Gram-stain-negative, obligatory anaerobic spirochaete (RCC2812 $)$ was isolated from a faecal sample obtained from an individual residing in a remote Amazonian community in Peru. The bacterium showed highest $16 \mathrm{~S}$ rRNA gene sequence similarity to the pig intestinal spirochete Treponema succinifaciens (89.48\%). Average nucleotide identity values between strain RCC2812 and all available Treponema genomes from validated type strains were all $<73 \%$, thus clearly lower than the species delineation threshold. The DNA G+C content of RCC $2812^{\top}$ was $41.24 \mathrm{~mol} \%$. Phenotypic characterization using the API-ZYM and API $20 \mathrm{~A}$ systems confirmed the divergent position of this bacterium within the genus Treponema. Strain RCC2812 ${ }^{\top}$ could be differentiated from the phylogenetically most closely related T. succinifaciens by the presence of alkaline phosphatase and $\alpha$ - glucosidase activities. Unlike T. succinifaciens, strain RCC $2812^{\top}$ grew equally well with or without serum. Strain RCC2812 is the first commensal Treponema isolated from the human faecal microbiota of remote populations, and based on the collected data represents a novel Treponema species for which the name Treponema peruense sp. nov. is proposed. The type strain is RCC2812 ${ }^{\top}$ (=LMG $31794^{\top}=$ CIP $111910^{\top}$ ).
\end{abstract}

Bacteria from the genus Treponema are typically anaerobic, spiral-shaped, highly motile micro-organisms that are fastidious to culture [1]. This genus comprises a number of primary pathogens responsible for syphilis [2] and periodontal disease [3] in humans, as well as digital dermatitis [4] in cattle. Commensal treponemas have received considerably less attention, although they are commonly found in the gastrointestinal tract of some insects [5] and mammals such as pigs and cows $[6,7]$, as well as most primates [8] including humans [9-12]. Next-generation sequencing data have shed more light on the taxonomic diversity and distribution of autochthonous Treponema members of the human gut microbiota, uncaptured by culturing methods. Treponema species have been consistently recognized as members of the faecal microbiome of humans living a traditional lifestyle, remote from industrialization, across continents, climates [11-13] as well as in extinct human populations (ancient humans from Mexico)
[14]. To reveal any key functional role associated to these conserved gut microbes, characterization of cultured representatives is essential.

A previous cross-sectional metagenomic exploration revealed that Treponema was one of the dominant members of the gut microbiome of remote Matsés tribe populations living in small settlements along the rivers of the Peruvian Amazon. Subsequent genome reconstructions from that population suggested that these commensal Treponema strains fell outside the known pathogenic clades and were more similar to Treponema succinifaciens [15]. Here we report on strain RCC2812 ${ }^{\mathrm{T}}$, recovered from a human stool sample as part of the Flora Intestinal Nativa project, an integrated study of the effect of industrialization on the gut microbiota of Peruvian populations (unpublished). On the basis of the information obtained from a polyphasic taxonomic approach, we propose

Author affiliations: 'Laboratory of Molecular Bacteriology, Department of Microbiology and Immunology, Rega Institute, KU Leuven, Leuven, Belgium; ${ }^{2}$ Center for Microbiology, VIB, Leuven, Belgium; ${ }^{3}$ Centre for Integrative Biology (CIBIO), Università degli Studi di Trento (UNITN), Trento, Italy; ${ }^{4}$ Université de Nantes, CNRS UMR 6004, LS2N, Nantes, France; ${ }^{5}$ Department of Biochemistry and microbiology, Universiteit Gent, Gent, Belgium; ${ }^{6}$ Department of Genetic Counseling, College of Health Professions, University of Arkansas for Medical Sciences, Little Rock, AR, USA; ${ }^{7}$ Centro Nacional de Salud Publica, Instituto Nacional de Salud, Lima, Peru; ${ }^{8}$ Centro Nacional de Salud Intercultural, Instituto Nacional de Salud, Lima, Peru.

*Correspondence: Claire Belkhou, claire.belkhou@kuleuven.vib.be; Jeroen Raes, jeroen.raes@kuleuven.vib.be Keywords: faeces; gut; human; microbiome; spirochaete; Treponema.

Abbreviation: ANI, average nucleotide identity; DDH, DNA-DNA hybridization; FAA, fastidious anaerobe agar; FBS, foetal bovine serum; OrthoANI, orthologous average nucleotide identity; OTEB, oral Treponema enrichment broth.

The GenBank accession number for the $16 \mathrm{~s}$ rRNA gene sequence of Treponema peruense RCC2812 is MW159752. The GenBank accession number for the genome is CP064936.

Four supplementary tables and one supplementary figure are available with the online version of this article. $005050 \odot 2021$ The Authors 


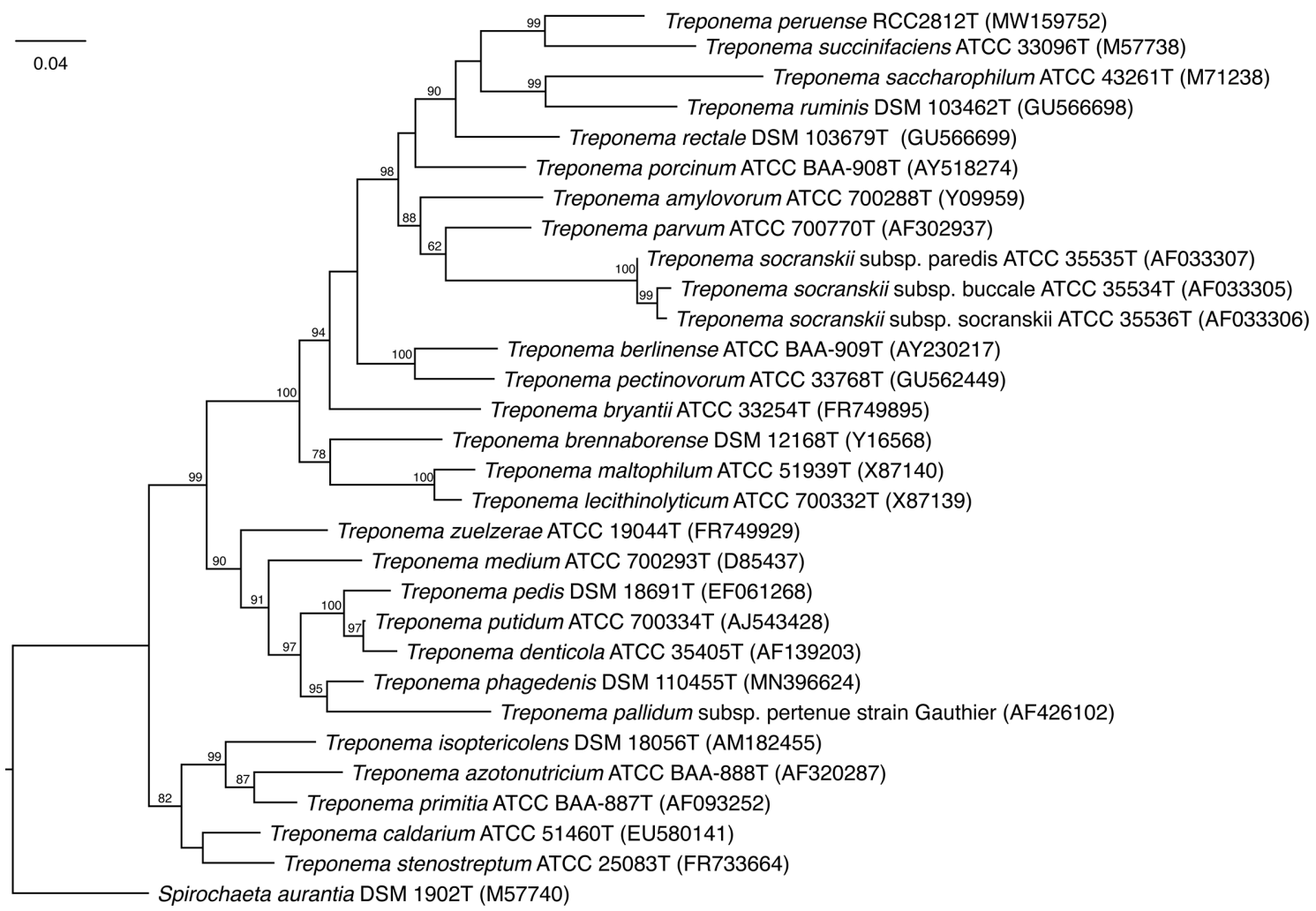

Fig. 1. Phylogenetic analysis of $16 \mathrm{~S}$ rRNA genes from all species of the genus Treponema presently recognized along with isolate RCC2812 $2^{\top}$. This phylogenetic tree was generated with FastTree using the maximum-likelihood method, based on the generalized timereversible model (there were a total of 1242 nucleotide positions in the final dataset). Bootstrap values (only those $>70 \%$ are shown) based on 1000 replicates are shown at the branch nodes for the maximum-likelihood method. GenBank accession numbers are indicated in parentheses. Bar: 0,04 nucleotide substitutions per site.

that $\mathrm{RCC} 2812^{\mathrm{T}}$ represents a novel species within the genus Treponema.

\section{ISOLATION AND ECOLOGY}

Strain RCC2812 $2^{\mathrm{T}}$ was isolated from a human stool sample, collected from a seemingly healthy 29 -year-old male resident of the Remoyacu village in the Peruvian Amazonian jungle, in the framework of the Flora Intestinal Nativa project (unpublished). The stool sample was collected within $30 \mathrm{~min}$ after defecation and stored in a $5 \mathrm{ml}$ tube with $50 \%(\mathrm{v} / \mathrm{v})$ of glycerol and frozen immediately at $-80^{\circ} \mathrm{C}$. It was transported to our lab on dry ice and further preserved at $-80^{\circ} \mathrm{C}$. $16 \mathrm{~S}$ rRNA gene sequence analysis revealed that the sample was highly enriched in Treponema (30\% of relative abundance). A sample aliquot of $200 \mathrm{mg}$ (wet weight) was enriched in oral Treponema enrichment broth (OTEB; Anaerobe Systems) containing $10 \%$ foetal bovine serum (FBS; Gibco), $25 \mu \mathrm{g} \mathrm{ml}^{-1}$ rifampin (Sigma-Aldrich) and $5 \mu \mathrm{g} \mathrm{ml}^{-1}$ enrofloxacin (SigmaAldrich) for $24 \mathrm{~h}$ at $37^{\circ} \mathrm{C}$ in an anaerobic chamber $\left(\mathrm{N}_{2} / \mathrm{H}_{2} /\right.$ $\mathrm{CO}_{2}, 80: 10: 10,37^{\circ} \mathrm{C}$ ), as previously described [16-18]. The enriched culture was diluted in OTEB and plated on fastidious anaerobe agar (FAA; Lab M), supplemented with $5 \%$ defibrinated sheep blood (Sanbio), $25 \mu \mathrm{g} \mathrm{ml}^{-1}$ rifampin and $5 \mu \mathrm{g} \mathrm{ml}^{-1}$ enrofloxacin. Single colonies were picked after $48-72 \mathrm{~h}$, sub-cultured in the broth described above and selected for further characterization based on spiral shape cell morphology, determined using a phase contrast microscope. Isolates were preserved at $-80^{\circ} \mathrm{C}$ in OTEB broth supplemented with $10 \%(\mathrm{v} / \mathrm{v})$ FBS, 5\% (v/v) dimethyl sulfoxide and $5 \%(\mathrm{v} / \mathrm{v})$ glycerol. Selected isolates were also subjected to alkaline lysis followed by thermal lysis $\left(15 \mathrm{~min}\right.$ at $\left.95^{\circ} \mathrm{C}\right), 16 \mathrm{~S}$ rRNA was then amplified by PCR using AccuPrime Taq DNA polymerase (Invitrogen) with primers fD1 (5'-AGAGTTTGATCCTGGCTCAG-3') and rP2 (5'-ACGGCTACCTTG TTACGACTT-3') [19]. Primer rP2 was used for Sanger sequencing (Eurofins Genomics). The sequences obtained were taxonomically assigned using NCBI BLAST. One isolate tentatively allocated to the genus Treponema, RCC $2812^{\mathrm{T}}$, was further characterized taxonomically.

\section{S rRNA GENE PHYLOGENY}

High molecular weight DNA was isolated from RCC2812 using the Puregene cell and tissue kit (Qiagen) according to the manufacturer's instructions. A standard SMRTbell library with $10 \mathrm{~Kb}$ insertions was generated, after which PacBio long reads were sequenced on the PacBio Sequel 
(a)

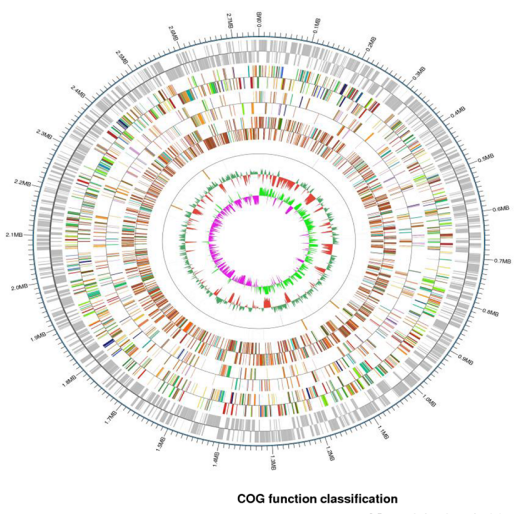

(c)

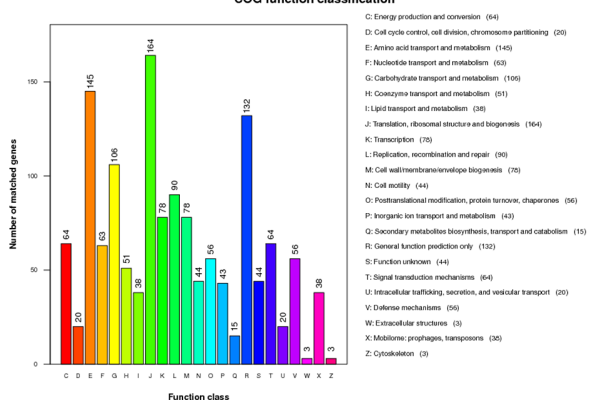

(b)

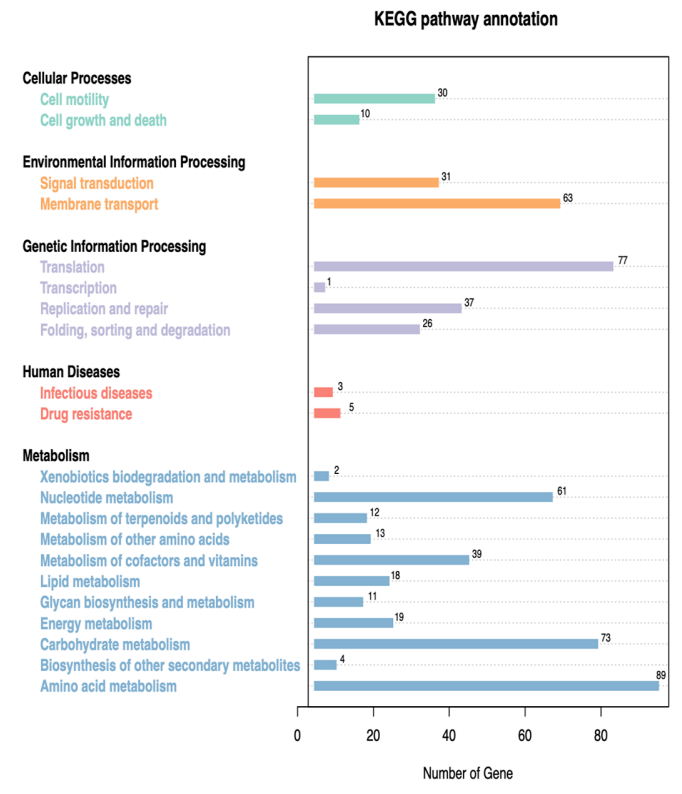

Fig. 2. (a) Genome representation of strain $\mathrm{RCC} 812^{\top}$ mapping from the outside to the inside of the circle: all predicted genes, cog, kegg, go, non-coding RNA, G+C content and $G+C$ skew, (b) gene predictions with $C O G$ and (c) KEGG.

System (Pacific Biosciences) with SMRTbell Template Prep Kit 1.0-SPv3 (Pacific Biosciences). Library construction and sequencing was performed at Novogene. Sequencing reads were assembled into one circular chromosome representing the RCC $2812^{\mathrm{T}}$ genome with coverage $>400 \times$. In order to more accurately determine the evolutionary relationships of strain RCC $2812^{\mathrm{T}}$ with other Treponema species, we retrieved the $16 \mathrm{~S}$ rRNA gene identified in its genome sequence. Four copies of the 16S rRNA gene were found in three distinct operons across the genome [1007688-1 169243(+); 2239131-2240673(-) and 2467010-2468552(-)], they all share above $99 \%$ sequence identity. We performed a search of the 16S rRNA genes against the EzBioCloud 16S rRNA gene database [20], which identified T. succinifaciens DSM $2489 \mathrm{~T}$ as the closest species with a similarity of $89.48 \%$ (for all four copies of the $16 \mathrm{~S}$ rRNA gene of strain RCC2812 ${ }^{\mathrm{T}}$ ). MUSCLE alignment of the 16S rRNA genes of all Treponema type strains along with one of the 16S rRNA copies of RCC2812 ${ }^{\mathrm{T}}$ (1167707-1169238_DIR+=accession MW159752) allowed a FastTree maximum-likelihood phylogenetic tree reconstruction (Fig. 1). This analysis suggested that isolate RCC $2812^{\mathrm{T}}$ probably represents a novel Treponema species most closely related to $T$. succinifaciens and falls within a clade of commensal Treponema originating from the gastrointestinal tract of different mammalian hosts. Similar results were obtained using the neighbour-joining method (see Fig. S1, available in the online version of this article).

We further confirmed that strain RCC $2812^{\mathrm{T}}$ was a novel species by computing the orthologous average nucleotide identity (OrthoANI [21]) between the genome of RCC2812 and the genome of the other Treponema species whenever available (see Table S1 for a list of all analyses performed on Treponema type strains). The ANI was consistently $<73 \%$ against RCC2812 ${ }^{\mathrm{T}}$ across all pairwise comparisons, the highest being $72.2 \%$ with T. succinifaciens (see Table S2), well below the $95 \%$ threshold for species delineation. Similarly, genome-to-genome distance calculation [22] from the DSMZ culture collection (http://ggdc.dsmz.de/) corroborated that RCC $2812^{\mathrm{T}}$ was a new species, with all estimated DNA-DNA hybridization (DDH) values being below 23\% (see details in Table S3).

\section{GENOME FEATURES}

The genome of RCC2812 2 comprises one chromosome of $2738066 \mathrm{bp}$, with a $\mathrm{G}+\mathrm{C}$ content of $41.24 \mathrm{~mol} \%, 2580$ predicted genes and no detected plasmids. As a reminder, the closest type strain T. succinifaciens DSM $2489^{\mathrm{T}}$ possesses one chromosome of 2897425 bp with a G+C content of $39.13 \mathrm{~mol} \%$, 2786 predicted genes and a plasmid of $165572 \mathrm{bp}$ [23]. Out of the 2580 predicted genes of RCC $2812^{\mathrm{T}}$ only 1190 have a match in the genome of Treponema succinifaciens DSM $2489^{\mathrm{T}}$ according to the NCBI-BLAST non-redundant (nr) database), 2033 were functionally annotated using the NCBI-BLAST non-redundant database (version 201611), 1919 using KEGG (version 201801) and 1294 using COG (see details in Fig. 2).

To determine if genomes similar to strain $\mathrm{RCC} 2812^{\mathrm{T}}$ have been identified in other metagenomic datasets, we computed the average nucleotide identity of RCC $2812^{\mathrm{T}}$ against all the Treponema species genomes available in the Unified Human 


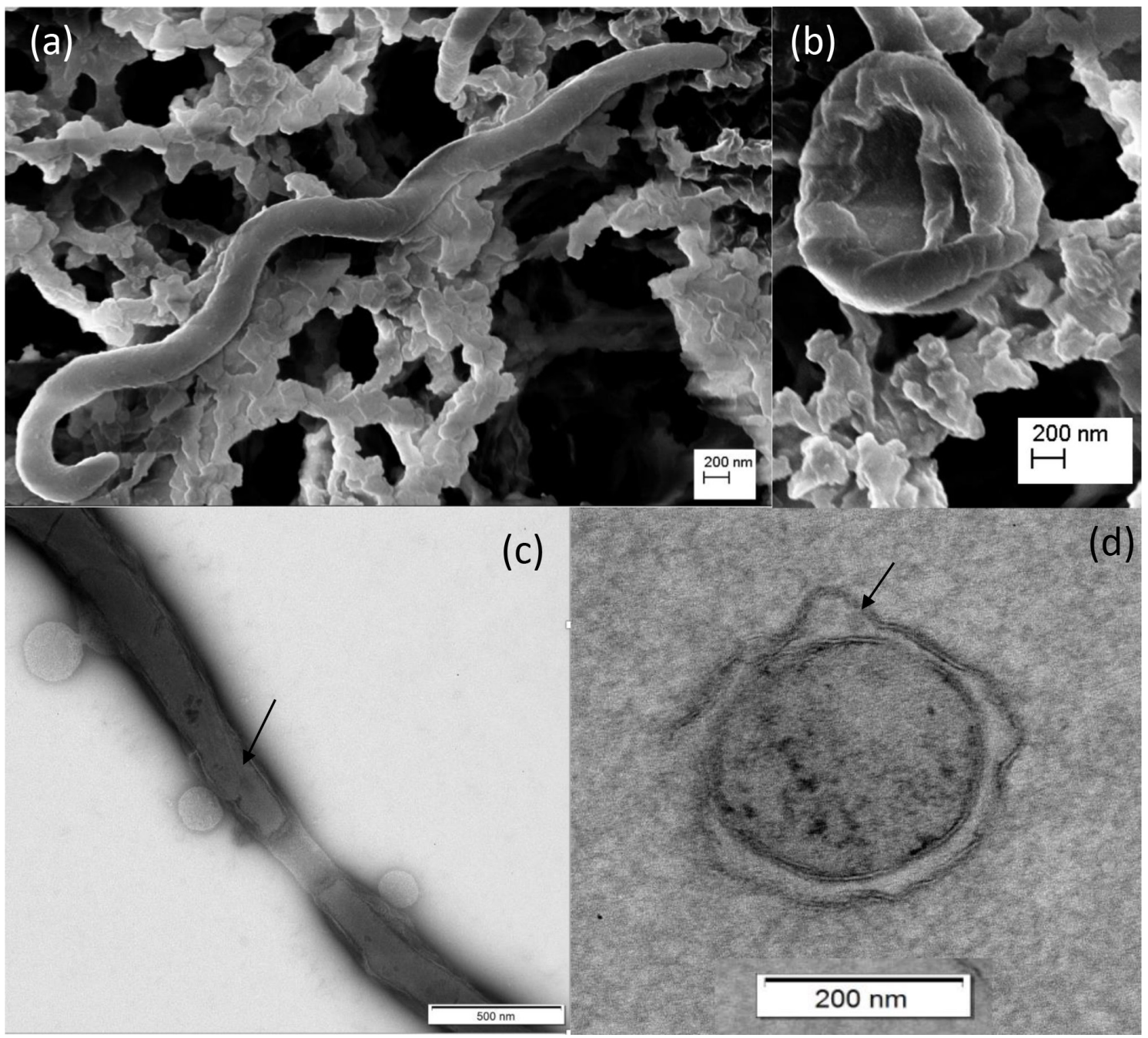

Fig. 3. (a and b): Conventional scanning electron microscopy images of RCC2812 (a, in spiral shape, b, in cystic form). (c): Transmission electron microscopy images of RCC2812 $2^{\top}$ with negative staining (arrow showing one of the two periplasmic fibrils originating subterminally from the end of the protoplasmic cylinder). (d) Conventional transmission electron microscopy image of a thin side section of a RCC $2812^{\top}$ cell (arrow showing again two periplasmic fibrils in bundle surrounded by the outer sheath).

Gastrointestinal Genome collection [24]. We identified 53 genomes with an average nucleotide identity above $95 \%$, indicating this species is present in other metagenomic datasets (see Table S4). Interestingly, this species of Treponema was only identified in datasets from remote and rural unindustrialized populations: in Latin America (seven from a rural village in El Salvador [25], 29 from Peru [15, 25], Africa (five from rural communities in Madagascar [26], seven from Tanzania [13]) and Oceania (five from rural agrarian communities in the Fiji Islands [27], having the highest prevalence in Peru (around $11 \%$ of samples).

\section{MORPHOLOGY AND PHYSIOLOGY}

Cells of strain RCC2812 $2^{\mathrm{T}}$ stain Gram-negative and appear, under a phase contrast microscope, as highly motile with a helical coil. Using electron microscopy (see Fig. 3),
RCC2812 ${ }^{\mathrm{T}}$ exhibited all typical cell morphology features of the genus: small, helical spirochaete with four periplasmic flagella in a 2:4:2 arrangement. Cells were approximately 4-6 $\mu \mathrm{m}$ long and had a diameter of $0.2-0.3 \mu \mathrm{m}$ with two to five spirals.

RCC2812 $2^{\mathrm{T}}$ displays good growth on FAA plates supplemented with $10 \% \mathrm{FBS}$ and $5 \%$ defibrinated sheep blood at $37^{\circ} \mathrm{C}$ under anaerobic conditions, but grows equally well without serum or blood. On the contrary, T. succinifaciens can grow on FAA plates without blood but grows poorly without serum. After 48 to $72 \mathrm{~h}$ on FAA, strain RCC $2812^{\mathrm{T}}$ produces punctiform translucent non-pigmented colonies with a diameter of approximately $0.5 \mathrm{~mm}$, smooth surface and a slight cream colour. No local haemolysis was observed after 4 weeks of plate culture. The strain reaches stationary phase in unsupplemented OTEB within $72 \mathrm{~h}$. The strain is mesophilic, 


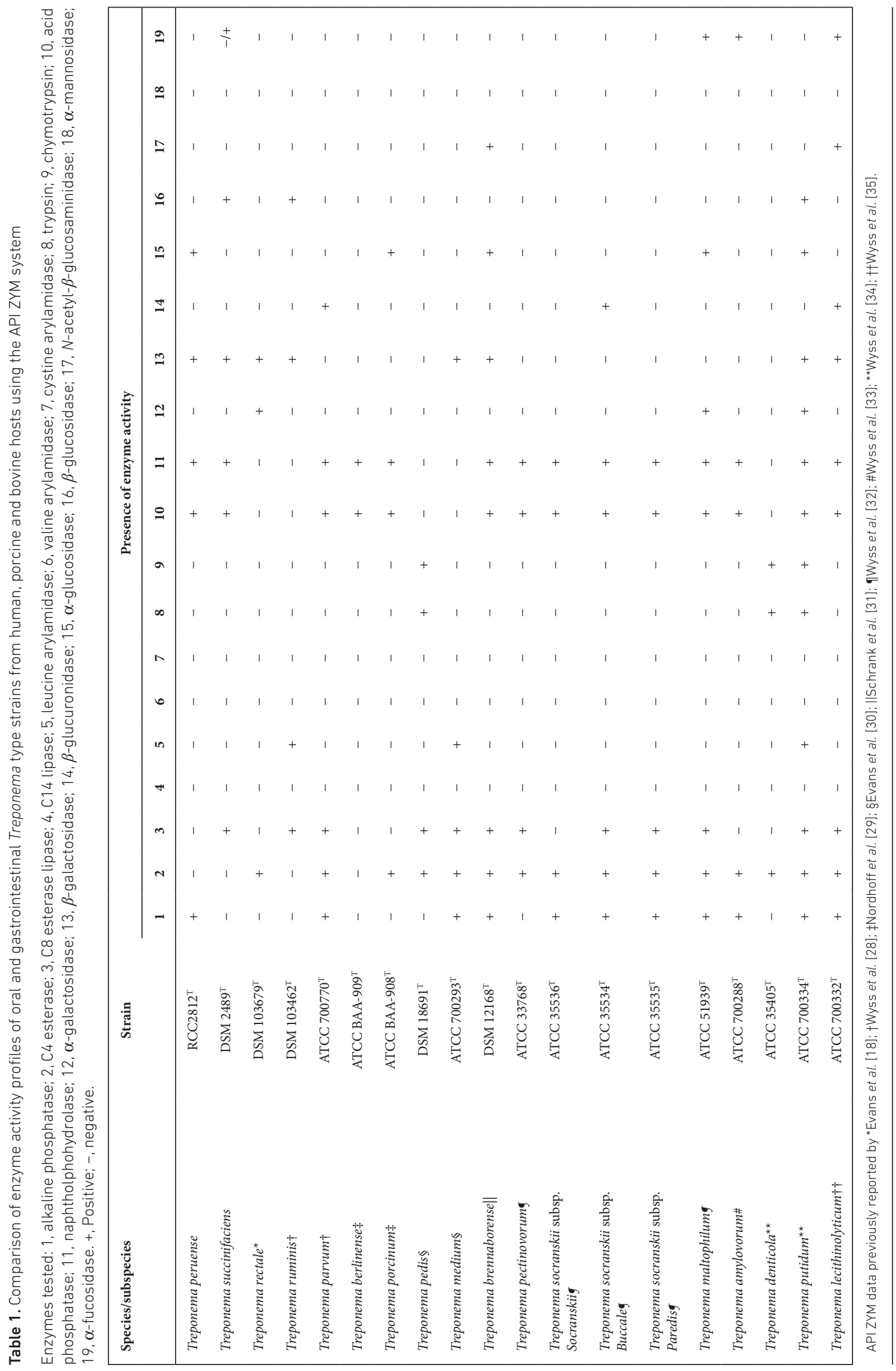


with growth temperatures ranging from $20-37^{\circ} \mathrm{C}$. Strain RCC $2812^{\mathrm{T}}$ is catalase-negative.

Further phenotypic characterization using the API ZYM system (bioMérieux) confirmed that strain RCC2812 ${ }^{\mathrm{T}}$ represents a phenotypically distinct species within the genus Treponema (see Table 1). The API ZYM test inoculum was prepared by harvesting cells from three fully grown FAA plates supplemented with 10\% FBS and 5\% sheep blood incubated for $48 \mathrm{~h}$. API ZYM test series were determined four times following the manufacturer's instructions. Of all tested activities, only alkaline phosphatase, acid phosphatase, naphtholAS-BI-phosphohydrolase, $\beta$-galactosidase and $\alpha$-glucosidase activities were positive. As API ZYM data for the phylogenetically closest species T. succinifaciens DSM $2489^{\mathrm{T}}$ were not previously reported, this strain was also included in the API ZYM test series. Strain DSM $2489^{\mathrm{T}}$ exhibited esterase lipase (C8), acid phosphatase, naphthol-AS-BI-phosphohydrolase, $\beta$-galactosidase, $\beta$-glucosidase and slight $\alpha$-fucosidase activities; all other reactions were negative.

In addition, strain RCC $2812^{\mathrm{T}}$ was also compared to $T$. succinifaciens DSM2489 $9^{\mathrm{T}}$ using API 20A and API rapid ID32 test series (bioMérieux) following the manufacturer's instructions. Bacterial inocula were prepared by harvesting cells from three FAA fully grown plates per strain supplemented with $10 \%$ FBS and $5 \%$ sheep blood after $48 \mathrm{~h}$ of incubation. In API $20 \mathrm{~A}$, strain RCC $2812^{\mathrm{T}}$ was positive for acidification of D-glucose, lactose, sucrose, maltose and D-mannose. On the contrary, T. succinifaciens DSM $2489^{\mathrm{T}}$ was also positive for acidification of maltose but not of D-glucose, lactose, sucrose and instead it was positive for D-xylose and cellobiose.

Using API rapid ID32, RCC2812 ${ }^{\mathrm{T}}$ was positive for $\beta$-galactosidase, $\quad \beta$-galactosidase-6-phosphate and $\alpha$-arabinosidase. T. succinifaciens DSM $2489^{\mathrm{T}}$ shared only $\beta$-galactosidase activity with RCC $2812^{\mathrm{T}}$. Contrary to RCC2812 $2^{\mathrm{T}}$, T. succinifaciens DSM $2489^{\mathrm{T}}$ had in addition $\alpha$-glucosidase and $\beta$-glucosidase activities.

To determine the main fermentation products of strain RCC $2812^{\mathrm{T}}$, a few colonies were harvested from FAA plates supplemented with $10 \%$ FBS and incubated in unsupplemented OTEB broth for $48 \mathrm{~h}$. The culture was then centrifuged for $10 \mathrm{~min}$ at 2000 r.p.m. The resulting supernatant was used for HPLC analysis using Aminex HPLC columns (Bio-Rad Laboratories). T. succinifaciens DSM $2489^{\mathrm{T}}$ was used for reference, and OTEB medium as negative control. The major fermentation products of both Treponema strains were formate and acetate, followed by succinate and lactate that were produced in smaller amounts.

\section{DESCRIPTION OF TREPONEMA PERUENSE SP. NOV.}

Treponema peruense (pe.ru.en'se. N.L. neut. adj. peruense pertaining to Peru, where the sample from which the novel species was isolated came from).
Cells are Gram-stain-negative and highly motile under phase contrast microscopy. Under electron microscopy, cells appear as small, helical spirochaetes with four periplasmic flagella in a 2:4:2 arrangement, $4-6 \mu \mathrm{m}$ long and with a diameter of $0.2-0.3 \mu \mathrm{m}$, and with two to five spirals. Strain RCC $2812^{\mathrm{T}}$ is a strict anaerobe that reaches stationary phase in unsupplemented OTEB medium after $72 \mathrm{~h}$. When grown on FAA plates supplemented with $10 \% \mathrm{FBS}$ at $37^{\circ} \mathrm{C}$ under anaerobic conditions for $48 \mathrm{~h}$, it produces punctiform translucent non-pigmented colonies with a diameter of approximately $0.5 \mathrm{~mm}$, smooth surface and a slight cream colour. In the API-ZYM system, strain RCC $2812^{\mathrm{T}}$ exhibited the following enzymatic activities: alkaline phosphatase, acid phosphatase, naphthol-AS-BI-phosphohydrolase, $\beta$-galactosidase and $\alpha$-glucosidase. In API $20 \mathrm{~A}$ assays, strain RCC $2812^{\mathrm{T}}$ tested positive for acidification of $\mathrm{D}$-glucose, lactose, sucrose, maltose, D-mannose, raffinose and L-arabinose. Major fermentation products formed in OTEB medium were formate, acetate, succinate and lactate. The genome of this strain comprises one chromosome of $2738066 \mathrm{bp}$, with a $\mathrm{G}+\mathrm{C}$ content of $41.24 \mathrm{~mol} \%, 2580$ predicted genes and no detected plasmid. On the basis of polyphasic taxonomic data presented here, we suggest recognition of RCC $2812^{\mathrm{T}}$ as a novel species within the genus Treponema for which the name Treponema peruense is proposed. The type strain is RCC2812 $2^{\mathrm{T}}\left(=\mathrm{LMG} 31794^{\mathrm{T}}=\mathrm{CIP} 111910^{\mathrm{T}}\right)$ and was isolated from a faecal sample obtained from an individual residing in a remote Amazonian community in Peru.

Funding information
Fonds Wetenschappelijk Onderzoek - Vlaanderen: Research funding
FWO G0B7320N, C.B. is funded by FWO through a PhD fellowship (no.
11 ZF416N), R.T.T. is funded by FWO through a postdoctoral fellowship
(no. 1234321 N), R.B. is funded by FWO through a postdoctoral fellow-
ship (no. 1221620 N). Katholieke Universiteit Leuven, Rega Institute for
Medical Research, Vlaams Instituut voor Biotechnologie.

Acknowledgements

We would like to thank the Peruvian participants, specially the Matsés community from Remoyacu, the personnel at the medical post in Colonia Angamos, the field team of the project Flora Intestinal Nativa, the Peruvian NIH and DIRESA (Regional Health Direction) Loreto. We would also like to thank the Electron Microscopy (EM) platform of the VIB Bioimaging Core Leuven for their help with the EM pictures of strain RCC2812 $2^{\top}$ as well as Kristel Bernaerts lab for their contribution to the metabolic profiling.

Conflicts of interest

The authors declare that there are no conflicts of interest.

Ethical statement

The protocol for this study was reviewed and approved by the Ethics Committee of the Peruvian National Institute of Health (protocol OEE010-15), who provided periodic monitoring during the execution of the project.

References

1. Staton GJ, Newbrook K, Clegg SR, Birtles RJ, Evans NJ, et al. Treponema rectale sp. nov., a spirochete isolated from the bovine rectum. Int J Syst Evol Microbiol 2017;67:2470-2475.

2. Forrestel AK, Kovarik CL, Katz KA. Sexually acquired syphilis: Historical aspects, microbiology, epidemiology, and clinical manifestations. J Am Acad Dermatol 2020;82:1-14. 
3. Asai $Y$, Jinno $T$, Igarashi $H$, Ohyama $Y$, Ogawa $T$. Detection and quantification of oral treponemes in subgingival plaque by realtime PCR. J Clin Microbiol 2002;40:3334-3340.

4. Demirkan I, Carter SD, Winstanley C, Bruce KD, McNAIR NM, et al. Isolation and characterisation of a novel Spirochaete from severe virulent ovine foot rot. J Med Microbiol 2001;50:1061-1068.

5. Schnorr SL, Hofman CA, Netshifhefhe SR, Duncan FD, Honap TP, et al. Taxonomic features and comparisons of the gut microbiome from two edible fungus-farming termites (Macrotermes falciger; M. natalensis) harvested in the Vhembe district of Limpopo, South Africa. BMC Microbiol 2019;19.

6. Cwyk WM, Canale-Parola E. Treponema succinifaciens sp. nov., an anaerobic spirochete from the swine intestine. Arch Microbiol 1979:122:231-239.

7. Newbrook K, Staton GJ, Clegg SR, Birtles RJ, Carter SD, et al. Treponema ruminis sp. nov., a spirochaete isolated from the bovine rumen. Int J Syst Evol Microbiol 2017;67:1349-1354.

8. Manara S, Asnicar F, Beghini F, Bazzani D, Cumbo F, et al. Microbial genomes from non-human primate gut metagenomes expand the primate-associated bacterial tree of life with over 1000 novel species. Genome Biol 2019:20:299.

9. De Filippo C, Cavalieri D, Di Paola M, Ramazzotti M, Poullet JB, et al. Impact of diet in shaping gut microbiota revealed by a comparative study in children from Europe and rural Africa. Proc Natl Acad SciU S A 2010;107:14691-14696.

10. Schnorr SL, Candela M, Rampelli S, Centanni M, Consolandi C, et al. Gut microbiome of the Hadza hunter-gatherers. Nat Commun 2014;5:3654

11. Obregon-Tito AJ, Tito RY, Metcalf J, Sankaranarayanan K, Clemente JC, et al. Subsistence strategies in traditional societies distinguish gut microbiomes. Nat Commun 2015;6:6505.

12. Angelakis E, Bachar D, Yasir M, Musso D, Djossou F, et al. Treponema species enrich the gut microbiota of traditional rural populations but are absent from urban individuals. New microbes new Infect 2019;27:14-21.

13. Rampelli S, Schnorr SL, Consolandi C, Turroni S, Severgnini M, et al. Metagenome sequencing of the hadza hunter-gatherer gut microbiota. Curr Biol 2015;25:1682-1693.

14. Tito RY, Knights D, Metcalf J, Obregon-Tito AJ, Cleeland L, et al. Insights from characterizing extinct human gut microbiomes. PLOS One 2012;7:e51146.

15. Obregon-Tito AJ, Tito RY, Metcalf J, Sankaranarayanan K, Clemente JC, et al. Subsistence strategies in traditional societies distinguish gut microbiomes. Nat Commun 2015;6:6505.

16. Stamm L, Bergen HL, Shangraw KA. Natural rifampin resistance in Treponema spp. correlates with presence of N531 in RpoB rif cluster i. Antimicrob Agents Chemother 2001;45:2973-2974.

17. Evans NJ, Brown JM, Demirkan I, Murray RD, Vink WD, et al. Three unique groups of spirochetes isolated from digital dermatitis lesions in UK cattle. Vet Microbiol 2008;130:141-150.

18. Evans NJ, Brown JM, Murray RD, Getty B, Birtles RJ, et al. Characterization of novel bovine gastrointestinal tract Treponema isolates and comparison with bovine digital dermatitis treponemes. Appl Environ Microbiol 2011;77:138-147.

19. Parola P, Roux V, Camicas JL, Baradji I, Brouqui P, et al. Detection of ehrlichiae in African ticks by polymerase chain reaction. Trans $R$ Soc Trop Med Hyg 2000;94:707-708.
20. Yoon S-H, Ha S-M, Kwon S, Lim J, Kim Y, et al. Introducing EzBioCloud: A taxonomically united database of $16 \mathrm{~S}$ rRNA gene sequences and whole-genome assemblies. Int J Syst Evol Microbiol 2017:67:1613-1617.

21. Lee I, Kim YO, Park SC, Chun J. OrthoANI: An improved algorithm and software for calculating average nucleotide identity. Int J Syst Evol Microbiol 2016;66:1100-1103.

22. Meier-Kolthoff JP, Auch AF, Klenk HP, Göker M. Genome sequencebased species delimitation with confidence intervals and improved distance functions. BMC Bioinformatics 2013;14:60.

23. Han C, Gronow S, Teshima H, Lapidus A, Nolan M, et al. Complete genome sequence of Treponema succinifaciens type strain (6091). Stand Genomic Sci 2011:4:361-370.

24. Almeida A, Nayfach S, Boland M, Strozzi F, Beracochea M, et al. A unified sequence catalogue of over 280000 genomes obtained from the human gut microbiome. bioRxiv 2019:762682.

25. Pehrsson EC, Tsukayama P, Patel S, Mejía-Bautista M, Sosa-Soto G, et al. Interconnected microbiomes and resistomes in low-income human habitats. Nature 2016;533:212-216.

26. Pasolli E, Asnicar F, Manara S, Zolfo M, Karcher N, et al. Extensive unexplored human microbiome diversity revealed by oUnexplored Human Microbiome Diversity Revealed by Over 150000 genomes from metagenomes spanning age, geography, and lifeGenomes from Metagenomes Spanning Age, Geography, and Lifestyle. Cell 2019:176:649-662.

27. Cleary B, Brito IL, Huang K, Gevers D, Shea T, et al. Detection of low-abundance bacterial strains in metagenomic datasets by eigengenome partitioning. Nat Biotechnol 2015;33:1053-1060.

28. Wyss C, Dewhirst FE, Gmür R, Thurnheer T, Xue Y, et al. Treponema parvum sp. nov., a small, glucuronic or galacturonic aciddependent oral spirochaete from lesions of human periodontitis and acute necrotizing ulcerative gingivitis. Int J Syst Evol Microbiol 2001;51:955-962.

29. Nordhoff M, Taras D, Macha M, Tedin K, Busse HJ, et al. Treponema berlinense sp. nov. and Treponema porcinum sp. nov., novel spirochaetes isolated from porcine faeces. Int J Syst Evol Microbiol 2005;55:1675-1680.

30. Evans NJ, Brown JM, Demirkan I, Murray RD, Birtles RJ, et al. Treponema pedis sp. nov., a spirochaete isolated from bovine digital dermatitis lesions. Int J Syst Evol Microbiol 2009;59:987-991.

31. Schrank K, Choi BK, Grund S, Moter A, Heuner K, et al. Treponema brennaborense sp. nov., a novel spirochaete isolated from a dairy cow suffering from digital dermatitis. Int J Syst Bacteriol 1999;49 Pt 1:43-50.

32. Wyss C, Choi BK, Schupbach P, Guggenheim B, Gobel UB. Treponema maltophilum sp. nov., a small oral spirochete isolated from human periodontal lesions. Int J Syst Bacteriol 1996;46:745-752.

33. Wyss C, Choi BK, Schüpbach P, Guggenheim B, Göbel UB. Treponema amylovorum sp. nov., a saccharolytic spirochete of medium size isolated from an advanced human periodontal lesion. Int J Syst Bacteriol 1997;47:842-845.

34. Wyss C, Moter A, Choi B-. K, Dewhirst FE, Xue Y, et al. Treponema putidum sp. nov., a medium-sized proteolytic spirochaete isolated from lesions of human periodontitis and acute necrotizing ulcerative gingivitis. Int J Syst Evol Microbiol 2004;54:1117-1122.

35. Wyss C, Choi BK, Schüpbach P, Moter A, Guggenheim B, et al. Treponema lecithinolyticum sp. nov., a small saccharolytic spirochaete with phospholipase $\mathrm{A}$ and $\mathrm{C}$ activities associated with periodontal diseases. Int J Syst Bacteriol 1999;49 Pt 4:1329-1339. 